\title{
A PERCEPÇÃO DO ESPECTADOR ADOLESCENTE FRENTE ÀS DIVERSAS LINGUAGENS CINEMATOGRÁFICAS ${ }^{1}$
}

\section{The adolescent spectator perception of the several cinematographic languages}

\author{
Adriane Barbosa Borges ${ }^{a}$, Suelen Fernanda Canguçu Rodrigues ${ }^{b}$, \\ a Jornalista, Graduada pela Facvest - Lages/SC e Pós-graduanda do Curso de Comunicação Audiovisual da Pontifícia Universidade \\ Católica do Paraná, Curitiba, PR - Brasil, e-mail: adrianejornalista@yahoo.com.br

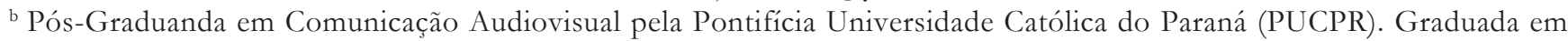 \\ Comunicação Social com habilitação em Jornalismo pela Universidade Estadual de Ponta Grossa (UEPG), Ponta Grossa, PR \\ -Brasil, e-mail: suelen_cangucu@yahoo.com.br
}

\begin{abstract}
Resumo
A partir do tema "Cinema como prática", este estudo teve como objetivo principal verificar o modo como adolescentes recebem filmes de diferentes linguagens. Para isso, realizou-se um Estudo de Recepção com um universo formado por 15 adolescentes, com faixa de idade entre 12 e 18 anos. A análise dos resultados foi fundamentada nos Estudos Culturais que entendem o espectador como sujeito ativo e crítico, não objeto passivo da "interpelação", considerando-se assim, por um lado, a espectatorialidade estruturada e determinada, e por outro, aberta e polimorfa. Foram levados em conta, também, os conhecimentos de arquétipo e de gêneros dramáticos dos pesquisados, pois a familiarização com essas estruturas é um elemento importante no processo de compreensão da narrativa fílmica.
\end{abstract}

Palavras-chave: Estudo de recepção; Cinema como prática social; Estudos culturais.

\footnotetext{
1 Trabalho apresentado à disciplina de Introdução aos Meios Audiovisuais - ênfase em Cinema, ministrada pela Prof. ${ }^{a}$ M. Celina do Rocio Paz Alvetti, no Curso de Pós-Graduação Lato Sensu em Comunicação Audiovisual, da Pontifícia Universidade Católica do Paraná.

Ana Laura Pinheiro Cruz, Andréa Micoski da Costa, Keyla Emy Sakata-Alunas de Pós-Graduação da PUCPR, Curitiba, PR - Brasil, que participaram da pesquisa.
} 


\begin{abstract}
From the subject "Cinema as practical", this study had as main objective verify how adolescents receive films from different languages. For this, was realized a Study of Reception with a universe formed by 15 adolescents, with age between 12 and 18 years old. The analysis of the results was based on the Cultural Studies that understand the spectator as asset and critic subject, not passive object of "interpellation", considering espectators structuralized and determined, and, on the other hand, opened. We also led in account, the knowledge of model and dramatical sorts, because the familiarization with these structures is an important element in the process of understanding the narrative.
\end{abstract}

Keywords: Study of reception; Cinema as social practical; Cultural studies.

\section{INTRODUÇÃO}

A partir da temática "Cinema como prática social", este estudo teve como objetivo geral verificar o modo como adolescentes recebem filmes de diferentes linguagens. Por meio de uma pesquisa de campo, buscou-se conhecer o comportamento deste público, com idade entre 12 e 18 anos, ${ }^{2}$ em relação a filmes de "cinema de entretenimento" e de "cinema arte", tentando reconhecer e comparar as formas de interpretação frente a distintas configurações cinematográficas.

Utilizou-se como ferramentas metodológicas a pesquisa em fontes bibliográficas e a realização de pesquisa de campo com grupo focal. O estudo foi dividido em três etapas: primeiramente fez-se uma revisão de literatura sobre a temática, para referenciar a pesquisa de campo. Partiu-se de uma abordagem onde se considera o cinema como prática social, buscando levantar uma discussão que reforça a sua contribuição como fonte e espaço para uma reflexão da história e realidade, imaginário e cultura.

Dando seqüência ao seu desenvolvimento, realizou-se uma pesquisa de campo (abordagem qualitativa) com um universo formado, inicialmente, por 15 jovens, contando-se ao final do estudo com 10 jovens, de classe média baixa, matriculados no ensino médio do Colégio Estadual Brasílio Vicente de Castro. ${ }^{3}$ Eles foram selecionados mediante um pré-requisito: ter assistido a "Homem Aranha 3" (Spider-Man 3 - EUA/2007 - Sam Raimi). Optouse por esse filme de aventura devido ao lançamento recente e com alta bilheteria, além de sua adequação à faixa etária do público-alvo deste estudo.

O filme narra a história de Peter Parker (Tobey Maguire). No terceiro filme da série, ele:

Conseguiu encontrar um meio-termo entre seus deveres como o Homem-Aranha e seu relacionamento com Mary Jane (Kirsten Dunst). Porém o sucesso como herói e a bajulação dos fãs, entre eles Gwen Stacy (Bryce Dallas Howard), faz com que Peter se torne autoconfiante demais epasse a negligenciar as pessoas que seimportam com ele. Porém a situação muda quando ele precisa enfrentar Flint Marko (Thomas Haden Church), mais conhecido como o HomemAreia, que possui ligações com a morte do seu tio Ben. Tendo que lidar com o sentimento de vingança, Peterpassa a usarum estranhouniforme negro, que se adapta ao seu corpo. ${ }^{4}$

O outro filme escolhido, para possibilitar uma discussão de análise fílmica dirigida, é de gênero diverso ao que serviu de pré-requisito: "Uma vida iluminada" (Everything is illuminated - EUA/

\footnotetext{
2 A delimitação da faixa etária foi feita com base no Estatuto da Criança e do Adolescente (Lei Federal nº 8.069, de 13 de julho de 1990), que considera adolescente (Artigo $2^{\circ}$ ) a pessoa entre 12 e 18 anos de idade.

3 A escolha do Colégio Estadual Brasílio Vicente de Castro deve-se ao fato de a integrante do grupo de pesquisa, Andréa Micoski da Costa, ser pedagoga deste, facilitando o contato das pesquisadoras com os pesquisados. O Colégio está localizado na região do CIC, em Curitiba/PR, e atende estudantes de classe média baixa.

4 Sinopse do site Adorocinema.com. Disponível em: <http://adorocinema.cidadeinternet.com.br/filmes/homem-aranha-3/ homem-aranha-3.asp>. Acesso em: 16 maio 2007.
} 
2005 - Liev Schreiber). Optou-se por esse filme dramático devido à consistência psicológica e edição lúdica, trilha sonora pulsante e fotografia de cores vivas (atraem a atenção). Este foi exibido em sessão organizada pelas pesquisadoras nas dependências do Colégio no dia 17 de maio de 2007.

Ele conta a trajetória de Jonathan (Elijah Wood):

um jovem judeu americano, que vai até a Ucrânia em busca da mulher que salvou a vida de seu avô na $2^{\mathrm{a}}$ Guerra Mundial. Ele é auxiliado nessa viagem por Alex Perchov (Eugene Hutz), um precário tradutor que mais atrapalha do que ajuda, e pelo avô de Alex, um motorista mal-humorado que anda sempre acompanhado de seu fedido e desobediente cachorro, batizado de Sammy Davis Jr. Durante a jornada o inusitado quarteto descobre segredos sobre a ocupação nazista e a cumplicidade do governo ucraniano da época. ${ }^{5}$

Procurou-se minimizar as diferenças entre "cinema comercial" e "cinema arte" ao se escolher dois filmes que têm como personagem central um jovem fazendo descobertas sobre si mesmo. Levantou-se a hipótese de que a semelhança na estrutura da narrativa das produções cinematográficas, embora fossem de gêneros diferentes, poderia contribuir para a decodificação da significação destas pelo público-alvo deste estudo.

Adotou-se como instrumento de pesquisa a formulação de entrevista semi-estruturada, visando interação do grupo, participação e exposição de sua leitura ativa acerca da temática proposta. A sessão realizada e o debate foram filmados pelas pesquisadoras, que em última etapa realizaram a análise desta investigação de campo. Foram observados os discursos utilizados pelo público, sua interpretação verbal e visual, e feitas reflexões a respeito das reações demonstradas.

\section{ESTUDOS CULTURAIS E TEORIA DA RECEPÇÃO}

"Os estudos culturais são reconhecidamente difíceis de definir, em virtude de sua metodologia deliberadamente eclética e aberta", expõe Stam (2003, p. 249). No que diz respeito a seu objeto de estudo, os estudos culturais interessam-se pela disseminação da cultura por meio do cinema e as conseqüências sobre o mundo. Seus teóricos chamam a atenção para as condições sociais e institucionais onde o sentido é produzido e recebido, para a interação entre textos, espectadores, instituições e o ambiente cultural.

Os estudos culturais investigam a cultura como um domínio no qual a subjetividade é construída. Para os estudos culturais, a subjetividade contemporânea está inextricavelmente entrelaçada com as representações midiáticas de todas as espécies. O sujeito é construído não apenas pela diferença sexual, mas também por muitos outros tipos de diferenças, em uma negociação permanente e multivalente entre condições materiais, discursos ideológicos e eixos sociais de estratificação fundados na classe, na raça, no gênero, na idade, na origem geográfica e na orientação sexual. Nesse sentido, os estudos culturais tentam abrir espaço para vozes marginalizadas e comunidades estigmatizadas. (STAM, 2003, p. 250).

Alguns teóricos de cinema consideram os estudos culturais uma traição desleal a um dos princípios fundadores dos estudos de cinema, o da especificidade do meio. Por isso, "os estudos culturais por vezes têm sido acusados de não serem críticos o suficiente, deixando-se enfeitiçar pela cultura de massa" (STAM, 2003, p. 251).

Mas a inovação dos estudos culturais é entender o espectador como ativo e crítico, não objeto passivo da "interpelação", mas a um só tempo constituidor do texto e por ele constituído. Dessa forma, os textos midiáticos não possuem um significado unívoco, podendo ser lidos de forma diversa por pessoas diferentes.

Quer dizer, "texto, dispositivo, discurso e história, em suma, encontram-se todos em jogo e em movimento. Nem o texto nem o espectador são entidades estáticas, pré-constituídas; os espectadores moldam a experiência cinematográfica e são por ela moldados, em um processo dialógico infinito" (STAM, 2003, p. 256).

Assim, se por um lado a espectatorialidade é estruturada e determinada,

\footnotetext{
Sinopse do site Adorocinema.com. Disponível em: < http://adorocinema.cidadeinternet.com.br/filmes/vida-iluminada/ vida-iluminada.as>. Acesso em: 16 maio 2007.
} 
por outro, é aberta e polimorfa. Por isso, David Morley define a espectatorialidade como o "momento em que os discursos do leitor encontram o discurso do texto" (MORLEY, 1980 apud STAM, 2003, p. 256). É esse o momento que o presente artigo estuda.

\section{POSSIBILIDADES DO OLHAR E DA REPRESENTAÇÃO}

Partindo-se do questionamento de como um grupo formado por adolescentes agiria ao assistir a duas produções cinematográficas de gêneros diferentes e narrativas semelhantes, para realizar a análise da recepção, considerou-se este público como sujeitos sociais ativos, que para ler uma produção cinematográfica partem de um repertório adquirido por meio da mediação propiciada pelo contexto histórico-social em que estão inseridos.

Sousa (1995, p. 82) defende que "о papel do receptor, leitor ou espectador não pode ser encarado como passivo, iludido ou alienado. A introdução de uma abordagem analítica que segue a direção à incorporação das subjetividades ou a construção de uma teoria do sujeito só pode se afirmar positivamente a realidade de sujeitos ativos".

Assume-se que este sujeito, o adolescente, decodifica as imagens (representação mental de objetos ou de sensações) a partir de vivências, lembranças e percepções passadas, passíveis de serem modificadas por novas experiências. Para que o espectador adote uma participação ativa, ele necessita observar os elementos significantes que compõem a enunciação e o enunciado do filme. Estes transmitem orientações para a interpretação da narrativa.

Alinhados ao pensamento de Turner (1997, p. 96), acreditamos que "[...] os filmes não são eventos culturais autônomos. Entendemos os filmes em termos de outros filmes, seu universo em termos de outros universos". Esta afirmação justifica a metodologia utilizada neste trabalho e leva-nos a problematizar a recepção dentro de um conceito de interpretação norteado pelo conhecimento (ou reconhecimento) de arquétipos, como forma estruturante que permite ao espectador produzir e partilhar sentidos e significados.

\section{CONHECIMENTO DE ARQUÉTIPO E GÊNERO}

No livro intitulado "A Jornada do Escritor", Vogler ajustou a teoria do monomito de Joseph Campbell (livro "O Herói de Mil Faces”), à estrutura dramática tradicional. A teoria de Campbell revela a existência de um esqueleto narrativo que, sem destruir a originalidade dos mitos de diferentes culturas, permanece o mesmo no fundo de todos os relatos, e lhes dão interesse universal. $\mathrm{Na}$ verdade, ele identifica uma fórmula narrativa comum presente nas antigas mitologias.

Fundamentado na obra de Campbell, Vogler (1998) mostra como o cinema usa essas estruturas míticas para criar histórias. Para ele, muitas das histórias que contamos hoje têm relação com os antigos mitos. Isso porque os personagens arquetípicos dos mitos fornecem a base da narrativa moderna.

Assim, usando estruturas míticas como base para roteiro, o autor busca enumerar todas as etapas de construção de personagens e situações presentes em grande parte das narrativas cinematográficas.

A primeira etapa refere-se a cada uma das personagens que são essenciais para qualquer tipo de história. Sempre existe um herói tentando vencer dificuldades externas ou internas. Sempre existe um mentor, uma pessoa que orienta o herói. Sempre existe um arauto, aquele que chama o herói para entrar logo na aventura.

A segunda etapa propõe estágios ou situações primárias para que a narrativa tenha boa fluência até o final. Na abertura, a apresentação do contexto (espaço-tempo), o status quo do mundo é pré-colocado. $\mathrm{O}$ antagonista aparece pela primeira vez e expõe seu objetivo. O protagonista é exibido em trecho do seu cotidiano, evidenciando as dificuldades que enfrenta. A pretexto dessas dificuldades, o protagonista expõe o seu desejo de mudança. Imediatamente em seguida, aparece o elemento ou ocorre a circunstância que o fará tomar o rumo dessa mudança. Ele recebe um chamado para a aventura. Um mentor o encoraja a encarar o desafio e partir rumo a sua missão. Não por acaso, o protagonista torna-se um empecilho entre o antagonista e seu objetivo. Acontece, então, o primeiro contato entre o protagonista e o antagonista, estabelecendo-se o conflito. É aí que o protagonista encontra seu amigo/ajudante, e 
com ele sela o compromisso de chegarem ao objetivo comum. Ocorre a primeira vitória parcial do protagonista, seguido do ápice. Mas acontece uma reviravolta do antagonista e o mundo do protagonista é ameaçado por ele. O antagonista afasta o protagonista. O protagonista, rebaixado, tem que dar a volta por cima. Acontece o confronto final entre os dois. O protagonista vence e o equilíbrio é restabelecido.

Alguns outros elementos parecem compor uma espécie de "tempero" do filme: $\mathrm{O}$ antagonista sempre é mais forte ou mais astuto que o protagonista; o protagonista geralmente apresenta um ponto fraco que é descoberto e explorado pelo antagonista; há sempre um personagem que serve para quebrar um pouco a tensão da história, uma criança bonitinha, um amigo desastrado; o antagonista morre ou sofre uma severa punição no final; muitas vezes o protagonista tenta salvar o antagonista de um destino miserável, mas falha, demonstrando que não combatia o antagonista por ser mau; etc.

Essa é, em poucas palavras, a tese de Christopher Vogler e explica o sucesso de alguns filmes. A partir desse livro, reconhece-se o modelo geral das histórias no cinema que pode ser usado para analisar diferentes películas. A familiarização com os arquétipos das histórias clareia a visão da estrutura que as rege, permitindo avaliá-las com mais critério, já que "o diretor utiliza os recursos oferecidos pela iconografia recombinando-os em formas que conciliam a familiaridade e a inovação" (STAM, 2003, p. 147).

Apesar dessa "fórmula mágica", cada filme apresenta, intrinsecamente, a forma como deve ser interpretado, de acordo com seus próprios sistemas de significação. Nesse contexto, o gênero é um elemento muito importante no processo de compreensão da narrativa. Nos filmes, o sentimento de identificação (e, conseqüentemente, de prazer) vem daquilo que é familiar, do reconhecimento das convenções, da repetição e da reiteração das situações presentes no repertório dos espectadores.

Um grande número de filmes [...] funciona maciçamente de acordo com uma identificação bastante monolítica, regulada por um fenômeno de reconhecimento, por uma tipologia estereotipada dos personagens: o bom, o mau, o herói, o traidor, a vítima etc. É possível dizer, nesse caso, que a identificação com o personagem procede de uma identificação de (e com o) personagem como tipo. A eficácia dessa forma de identificação não deixa dúvida, sua perenidade e quase universalidade são a prova disso: porque o efeito dessa estereotipagem é reativar de maneira totalmente comprovada, em um nível ao mesmo tempo rudimentar e profundo, os afetos saídos diretamente das identificações comos papéis da situação edipiana: identificação com o personagem portador do desejo contrariado, admirado e pelo herói que representa o ideal do eu, temor diante de uma figura paterna etc. (AUMONT, 1995, p. 267).

A relação do espectador com o filme é individual, estética e subjetiva, e este pode apresentar diferentes percepções segundo a categoria de público a que pertença. Aumont aponta que a identificação não é uma relação de tipo psicológico com este ou aquele personagem, mas depende antes de um jogo de lugares dentro da situação. Não conseguiríamos considerá-la como um fenômeno monolítico, estável, permanente, ao longo de todo o filme. Pode-se dizer que esta é mutável e construída, durante o tempo de exposição do filme, pelo espectador, a partir da narrativa em si, o que permite a este se identificar diegeticamente de forma diferenciada com esta ou aquela narrativa filmica, mesmo que semelhantes.

No processo de identificação, o trabalho da narração, da mostração, da enunciação, desempenha um papel completamente determinante: contribui amplamente para informar a relação do espectador com a diegese e com os personagens; é ele, no nível das grandes articulações narrativas, que vai modular permanentemente o saber do espectador sobre os acontecimentos diegéticos, que vai controlar, a cada instante, as informações de que dispõe à medida que o filme progride, que vai esconder alguns elementos da situação ou, ao contrário, antecipar outros, que vai regular o jogo do avanço e do atraso entre o saber do espectador e o suposto saber do personagem e induzir desse modo, permanentemente, a identificação do espectador com as figuras e as situações da diegese. (AUMONT, 1995, p. 281).

\section{RESULTADOS E DISCUSSÃO}

Turner (1997, p. 110) considera que "O ato de sair é intrínseco ao evento de ir ao cinema". Na pesquisa realizada, ao se exibir o filme "Uma vida iluminada" fora do ambiente 
do cinema, foi ocasionada a quebra deste ritual. Este fator foi levado em conta na análise feita pelo público do filme exposto, pois como nos alerta Stam (2003, p. 251), "diferentes meios [...] geram prazeres específicos".

Embora este fator possa ter influenciado o olhar do espectador, não torna menos pertinente este estudo, uma vez que a maioria do público pesquisado afirma assistir a pelo menos um filme por semana (pela televisão, computador e DVD), mas não vai ao cinema com a mesma freqüência.

Quando vai ao cinema, decide, antecipadamente, qual filme assistir, influenciados por opiniões do grupo familiar e de amigos, além da divulgação da mídia. Foram esses motivos que levaram todos eles a assistir ao filme "Homem Aranha 3" na semana de estréia. Confirmando a afirmação de Turner, (1997, p. 100), de que "não há publicidade que consiga atrair as pessoas para um filme de que elas não gostam e que não possam elogiar para os amigos".

Em geral, eles privilegiam filmes de ação e de terror, no estilo de "Kill Bill" e "Casa de Cera", respectivamente. Nenhum deles afirmou gostar de drama, gênero em que se enquadra o filme "Uma vida iluminada". Ainda de acordo com Turner (1997, p. 16), "o desejo de assistir a um filme popular está relacionado com toda uma gama de outros desejos - moda, novidade, posse de ícones ou signos altamente valorizados pelas outras pessoas do mesmo grupo de interesses, de mesma condição social ou faixa etária”. O que é foi facilmente percebido no resultado deste estudo de campo.

\section{COMPREENSÃO DAS DIVERSAS LINGUAGENS}

Para Turner (1997, p. 122), “[...] a maioria de nós que assiste a um filme sentirá que há algum limite ao tipo de leituras que se pode sujeitá-lo. Certos conjuntos de convenções, como as de gênero, parecem existir para organizar, [...], as várias respostas potenciais do público num ponto de vista único e homogêneo". Assim, ao se escolher expor os pesquisados a um filme que não está integrado ao seu repertório, enquanto prática social ou enquanto conteúdo do ambiente escolar poderse-ia obter uma resposta de rejeição à temática.

No entanto, a exposição do filme quebrando a rotina do ambiente escolar obteve resposta positiva dos alunos pesquisados. Ainda que a maioria tenha afirmado não ter gostado do filme "Uma Vida Iluminada" e ter gostado de "Homem Aranha 3", eles colaboraram satisfatoriamente com a pesquisa durante o debate temático.

Acredita-se que falta aos pesquisados o conhecimento de outros filmes do gênero drama (a maioria nunca havia assistido um filme desse tipo) que poderiam servir como referências importantes, oferecendo pontos de apoio para ancorar a compreensão, a reflexão e a avaliação do que estavam assistindo. "Steve Neale, por exemplo, sustentou que os gêneros eram 'sistemas de orientações, expectativas e convenções que circulam entre a indústria, o texto e o sujeito" (apud STAM, 2003, p. 148). Ou seja, os mitos repostos pelo gênero auxiliam a ler a história. A carência de repertório em relação ao drama foi um dos motivos da dificuldade constatada no entendimento de "Uma vida iluminada". Poucos souberam recontar resumidamente a narrativa dele.

Por outro lado, pode-se dizer que por ser a história de um judeu que vai à Ucrânia para investigar coisas da Segunda Guerra, pode ter pouca relação com a vida de adolescentes brasileiros não-judeus. Ou seja, houve um pouco de falta de contexto e os jovens não se identificaram com o protagonista, pois suas histórias de vida têm pouca familiaridade.

Dessa forma, a maioria deles demonstrou rejeição ao "Uma vida iluminada" por não conseguir interpretá-lo, revelando a dificuldade para "leitura" audiovisual de filmes com roteiro subjetivo e personagem onisciente. E, ao contrário, gostaram do "Homem Aranha 3" porque conseguiram decodificar os significantes familiares a eles pela exposição habitual ao cinema comercial onde estes códigos são comuns e padronizados.

Em decorrência, todos responderam que gostaram mais do filme "Homem Aranha 3", especialmente das cenas de luta e dos efeitos especiais, e acharam prazeroso assistir a esse filme. Quanto ao "Uma vida iluminada", embora todos tenham rido de algumas seqüências do filme, metade afirmou ter gostado. Os que gostaram, atribuíram isso ao enredo do filme. Os que não gostaram justificaram que a história é lenta e não acharam prazeroso assisti-lo porque é pesado e cansativo. Uma das respondentes disse que, apesar deste filme ser mais curto que o 
"Homem Aranha 3", teve a sensação de que era mais longo. Realmente, na filmagem da sessão é possível observá-los bocejando e se espreguiçando. Assim, poucos disseram que assistiriam ao "Uma vida iluminada" no cinema.

Apenas um dos pesquisados compreendeu facilmente a narrativa desse filme e o recebeu sem estranhamento. Ao longo da discussão revelou que costuma ler sinopses de filmes na Internet e fazer download dos que mais lhe atraem. Deste modo, tem acesso a variados modelos de cinema. O que o coloca junto dos autodidatas audiovisuais, comprovando que a prática cinematográfica está diretamente ligada à capacidade de "leitura" audiovisual advinda da experiência, do treino. É o exercício pessoal de tradução das representações que conduz ao domínio das linguagens do cinema.

Pode-se perceber que, para a maior parte dos adolescentes pesquisados, cinema é apenas distração. Tanto quanto assistir a filmes mais densos, a discussão cinematográfica é rara entre eles. Apenas um dos pesquisados discutiu um pouco de técnica, apesar de não usar os termos adequados (mencionou a narrativa em flashback, por exemplo, mas sem a determinar deste modo). Nenhum dos demais foi capaz de tecer considerações sobre a linguagem ou o tipo narrativo do filme. Também não fizeram discussões acerca das técnicas utilizadas (nem mesmo para os efeitos especiais do "Homem Aranha 3") e dos custos das produções. Tampouco analisaram o roteiro e os personagens profundamente em nenhum dos filmes. Nem avaliaram a fotografia, o figurino, a cenografia ou a trilha dos filmes, comprovando que vão ao cinema em busca, somente, de entretenimento e pouco importa a eles o que está por trás das produções que consomem.

\section{REFERÊNCIAS}

AUMONT, Jacques. A estética do filme. São Paulo: Papirus, 1995.

BRASIL. Estatuto da criança e do adolescente. Lei Federal 8069, de 13 de julho de 1990.

SINOPSE do site Adorocinema.com. Disponível em: <http://adorocinema.cidadeinternet.com.br/ filmes/homem-aranha-3/homem-aranha-3.asp $>$. Acesso em: 16 maio 2007.
SINOPSE do site Adorocinema.com. Disponível em: <http://adorocinema.cidadeinternet.com.br/ filmes/vida-iluminada/vida-iluminada.asp $>$. Acesso em: 16 maio 2007.

STAM, Robert. Introdução à teoria do cinema. Campinas: Papirus, 2003.

SOUSA, Mauro Wilton de. Sujeito, o lado oculto do receptor. São Paulo: Brasiliense, 1995.

TURNER, Graeme. Cinema como prática social. São Paulo: Summus, 1997.

VOGLER, Christopher. A jornada do escritor. Tradução de Ana Maria Machado. Rio de Janeiro: Nova Fronteira, 1998.

Recebido: 11/12/2007

Received: 12/11/2007

Aprovado: $17 / 12 / 2007$

Approved: 12/17/2007 